\title{
Uniting the field: using the ACRL Visual Literacy Competency Standards to move beyond the definition problem of visual literacy
}

Dana Thompson

Murray State University, dstatton@murraystate.edu

Stephanie Beene

University of New Mexico

Follow this and additional works at: https://digitalcommons.murraystate.edu/faculty

Part of the Information Literacy Commons

\section{Recommended Citation}

This is an Accepted Manuscript of an article published by Taylor \& Francis in Journal of Visual Literacy on May 4, 2020, available online: https://www.tandfonline.com/doi/full/10.1080/1051144X.2020.1750809

This Peer Reviewed/Refereed Publication is brought to you for free and open access by Murray State's Digital Commons. It has been accepted for inclusion in Faculty \& Staff Research and Creative Activity by an authorized administrator of Murray State's Digital Commons. For more information, please contact msu.digitalcommons@murraystate.edu. 
Uniting the field:

Using the ACRL Visual Literacy Competency Standards

to move beyond the definition problem of visual literacy

Corresponding Author:

Dana Statton Thompson, Murray State University

Email: dthompson29@murraystate.edu

ORCID: https://orcid.org/0000-0001-7967-3694

and Stephanie Beene, University of New Mexico

Email: sbeene@unm.edu

ORCID: https://orcid.org/0000-0003-3884-3962 


\begin{abstract}
Visual literacy has evolved alongside information literacy and media literacy, reflecting social, technological, and cultural changes. Rapidly advancing technology, multimodal access to information and disinformation, and political rhetoric increasingly impact the perception, trust, and use of visual media. These broader technological and cultural shifts also change what it means to be a visually literate individual in the twenty-first century. Although much has been written about visual literacy, there is very little that reviews scholarship that uses the 2011 ACRL Visual Literacy Competency Standards for Higher Education. Through an analysis of 196 articles published from 2011 to 2019, this study examines how the standards, which outline visual literacy competencies for learners in the twenty-first century, have been used since their adoption, by whom, and for what purposes. This study unveils an emerging shift in the paradigm of visual literacy scholarship.
\end{abstract}




\section{Introduction}

Visual literacy, much like information and media literacy, has evolved alongside social, technological, and cultural changes. Originally examined throughout the twentieth century within cognitive psychology, education, instructional design, photography, and semiotics, the twenty-first century saw visual literacy research expand into a range of disciplines. Librarianship joined other disciplines interested in visual literacy under the purview of information literacy. As librarians began to address rapid technological change and proliferating information resources, many of them newly online, the Association of College \& Research Libraries (ACRL) published the now rescinded Information Literacy Competency Standards for Higher Education (the Standards) in 2000. In the decade that followed, librarians began to investigate critical information literacy, metaliteracies, and multiple ways of looking, learning, and knowing.

In 2009, academic librarians interested in visual information created the ACRL Image Resources Interest Group, forming the first Visual Literacy Task Force in early 2010. ACRL charged the group with drafting a set of competency standards to complement the Standards and adopted the Visual Literacy Competency Standards for Higher Education (the Visual Literacy Standards) in spring 2011. The Task Force's article, 'Visual Literacy Standards in Higher Education: New Opportunities for Libraries and Student Learning,' promoted the Visual Literacy Standards as one method for librarians to develop student's critical understanding, use, and production of visual materials (Hattwig, Bussert, Medaille, \& Burgess, 2013). Three years later, members of the Task Force published the book, Visual Literacy for Libraries: A Practical, Standards-based Guide (Brown, Bussert, Hattwig, \& Medaille, 2016), providing librarians with practical ideas for 
instruction, including ideas for integrating the Visual Literacy Standards with the newly codified 2016 ACRL Framework for Information Literacy for Higher Education (the Framework).

Since the adoption of the Visual Literacy Standards, what constitutes a visually literate individual has shifted in light of new media, political messaging, and technology. For example, emerging technologies, including artificial intelligence, augmented and virtual realities, deep fakes, and disinformation, are impacting the perception, trust, and use of visual media (Tewell, 2016; Marwick \& Lewis, 2017; Mackey \& Jacobsen, 2019). To address some of these challenges, the ACRL formed a second Visual Literacy Task Force in 2018, of which the authors are members, to update the Visual Literacy Standards and align the Visual Literacy Standards with the Framework. Although much has been written about visual literacy, there is very little that reviews scholarship referencing or utilizing the Visual Literacy Standards. As a relatively recent addition to a field of study that spans decades and many academic disciplines, it is no surprise that a set of standards created by and for academic librarians has experienced little uptake in the larger visual literacy milieu. However, by examining how the standards have been used since their adoption, by whom, and for what purposes, this study unveils an emerging shift in the paradigm of visual literacy scholarship.

\section{Literature review}

As a multidisciplinary field, visual literacy remains challenging to analyze. Some of these challenges include widespread disagreements on definitions, measurements, scopes, and terms. Scholars have traced the eclecticism of visual literacy scholarship, noting the need to reach a 
better understanding of the field as a whole, including its future directions. Here, the authors outline the definition problem as well as trends in the literature.

\section{The definition problem}

Robert Tyler Davis refers to 'visual literacy' as early as 1939 as a necessary component within education in the United States (Davis, 1939 as cited in Peña Alonso, 2018). With near prescient insight into conversations still ongoing in the visual literacy community, Davis wrote:

Mere reading and writing are no longer sufficient. Literacy of many kinds is necessary for taking a responsible part in a more complex world ... Trained powers of observation which constitute visual literacy are essential. The exercise and training of visual perception is a concern of education in secondary schools, as it is of museum education. (Davis, 1939 as cited in Peña Alonso, 2018)

However, John Debes, one of the founders of the International Visual Literacy Association (IVLA), is usually credited with coining the term 'visual literacy' in 1969. He defined visual literacy as "a group of vision-competencies" developed "by seeing and at the same time having and integrating other sensory experiences" at the first First Annual National Conference on Visual Literacy (Debes, 1969, p. 27). Because of the interdisciplinary nature of visual literacy research, researchers struggled to agree upon an operational definition of visual literacy throughout the 1970s and 1980s, leading at one point to as many as 62 definitions (Cochran, 1976). 
A unified definition of visual literacy continues to elude scholars (Brumberger, 2019). However, scholars across a range of disciplines and subjects are beginning to reference and use the 2011 definition offered by the Visual Literacy Standards:

Visual literacy is a set of abilities that enables an individual to effectively find, interpret, evaluate, use, and create images and visual media. Visual literacy skills equip a learner to understand and analyze the contextual, cultural, ethical, aesthetic, intellectual, and technical components involved in the production and use of visual materials. A visually literate individual is both a critical consumer of visual media and a competent contributor to a body of shared knowledge and culture (ACRL, 2011).

As one metric for assessing the creation, evaluation, and use of visual information, the Visual Literacy Standards have supplied comprehensible, measurable guidelines for research and instruction across a variety of fields. As Brumberger notes, ACRL has proposed "what is perhaps the most extensive and tangible set of visual literacy abilities to date" (2019, p. 12).

Contemporary interpretations of visual literacy have expanded on ACRL's definition, framing it within broader social practices and constructs while recognizing metacognitive, individualized components. Reconceptualizing visual literacy in this way suggests that it is not a stable, universal set of cognitive skills, but a set of practices that varies with the context of the production, distribution, and reception of visual media (Serafini, 2017, p. 8). As a metaliteracy within a critical social justice framework, visual literacy empowers learners to (re)assess images and media with an eye toward decolonization, diversity, representation, and inclusion. Additionally, technological advances in the twenty-first century, such as artificial intelligence, 
augmented, immersive and virtual realities, deep fakes, linked open data, memes, social and digital media, video game design, and viral videos, are pushing the field into new territory.

\section{Mapping the research}

In its infancy during the 1970s to 1980s, an abundance of theories related to visual literacy proliferated, including visual communication, visual culture, visual language, and visual thinking, further complicating a unified approach and understanding of visual literacy as a concept. Indeed, in 1990, the first Delphi study of visual literacy reinvigorated the need for a more focused scope of research (Clark-Baca \& Braden, 1990). A second Delphi study seventeen years later produced inconclusive results, calling into question whether real consensus in the field could even be achieved (Brill \& Branch, 2007).

Scholars have noted that because the field of visual literacy is so varied, a clear and distinct

identity remains elusive (Kędra \& Žakevičiūtè, 2019; Brumberger, 2019). Nonetheless, research conducted in the past five years mapping disparate visual literacy scholarship has uncovered several threads uniting the field (Baylen \& Lucas, 2014; Michelson, 2017; Matusiak \& Heinbach, 2018; Peña Alonso, 2018; Brumberger, 2019). These scholars examine research methodologies and questions that have shaped the field. In turn, their conclusions and methods have informed the authors' research scope and methods, as detailed in the methodology section.

Michelson (2017), Baylen and Lucas (2014), Brumberger (2019), and Peña Alonso (2018) have traced emerging trends in visual literacy research, discovering similar results regarding broader trends in technology advancement, education, and research questions, which serves as the first thread uniting the field. Michelson (2017) searched for the phrase 'visual literacy' and found 
thousands of records dating back to the 1970s via Google Scholar and the Education Resources Information Center (ERIC) database. He analyzed his results by decade from 1970 until 2016, noting a growing interest from "scholars outside education, including significant numbers of librarians;" and a "re-enlivened discussion in [visual literacy]" sparked by the internet, which had "ensconced it as a significant topic of discourse" (Michelson, 2017, p. 98). Baylen and Lucas (2014) also discovered an increase in the use and integration of technology, examining 129 articles published from 2000 to 2014. Brumberger's conclusions (2019) upheld these findings, where broad research trends directly reflected technological advancements. She discovered such trends through a systematic evaluation of research questions in articles published within the Journal of Visual Literacy (JVL). In the most exhaustive review encountered by the authors, Peña Alonso's dissertation, Visualizing Visual Literacy (2018), yielded an initial bibliography of 2,400 articles spanning literature from 1908 to 2008 . He culled these to a dataset of 330 key articles, and through extensive analysis, discovered three waves of visual literacy research associated with the development of particular technologies, such as television and the internet, revealing similar trends as those identified in earlier research (Peña Alonso, 2018).

Brumberger (2019), Baylen and Lucas (2014), and Matusiak and Heinbach (2018) have all focused on the amount of empirical research in visual literacy scholarship, a second thread in the literature. For instance, Brumberger found that only $27 \%$ of the articles she examined (just 104 out of over 375) could be considered research articles, whereas the majority were instead pedagogical case studies or conceptual papers (Brumberger, 2019). Brumberger's data echoed Baylen and Lucas' determination (2014) that, although the JVL published extensively on visual and media literacy, the majority of those articles were not research-based, but instead focused on 
defining the field. In contrast, Matusiak and Heinbach (2018) analyzed the research methodologies of 30 articles published from 2011 and 2017 and indexed in two databases (Library and Information Science \& Technology Abstracts, and Communication and Mass Media Complete). They found that two-thirds of those studies qualified as qualitative and quantitative research, and that empirical research of visual literacy practices is an emergent area for library science, specifically (Matusiak \& Heinbach, 2018). Their finding indicates that the field of librarianship is interested in conducting empirical research on visual literacy to a higher degree than found by Brumerberger (2019) and Baylen and Lucas (2014).

Although the literature on visual literacy is vast, these two threads offer researchers a compelling path for inquiry moving into the twenty-first century. By exploring the research contexts surrounding the Visual Literacy Standards, the authors of this study examine the gaps exposed by Brumberger (2019), Baylen and Lucas (2014), and Matusiak and Heinbach (2018).

\section{Methods}

\section{Methodology}

This study is structured as a scoping review in that it is a "preliminary assessment of [the] potential size and scope of [the] available research literature" and "aims to identify [the] nature and extent of research evidence" (Grant \& Booth, 2009, p. 95). Khalil, Peters, Godfrey, McInerney, Soares, and Parker (2016) have determined that scoping reviews are "of particular use when a body of literature has not yet been comprehensively reviewed or exhibits a complex or heterogeneous nature not amenable to a more precise systematic review" (p. 118). The purpose of this study in particular is to summarize and disseminate research findings, to identify 
research gaps, and to make recommendations for future research as outlined by Arksey and O'Malley (2005). The following research question guided this study: What are the contexts in which the ACRL Visual Literacy Competency Standards for Higher Education is used to ground research? Broad questions, like this one, are characteristic of scoping reviews (Munn, Peters, Stern, Tufanaru, McArthur, \& Aromataris, 2018).

\section{Data collection}

The authors searched Google Scholar for the phrase 'acrl visual literacy competency standards' and imported results that fit particular inclusion/exclusion criteria into Airtable (a free, collaborative, cloud-based database). From the search result list, authors included research items published in English, from 2011, the year ACRL adopted the Visual Literacy Standards, until June 1, 2019, the date the authors stopped data collection. Data collection occurred over approximately 12 months. Research items included book chapters, conference proceedings, dissertations/theses, and journal articles, because of their typified characteristics, defined by their audiences, contexts, and purposes (Miller, 1984; Russo, Jankowski, Beene, \& Townsend, 2019). Book reviews, citations, dictionary/encyclopedia entries, handouts, library/course research guides, patents, and poster presentations, were excluded because they did not tend to include typified characteristics, such as abstracts, literature reviews, and citations necessary for analysis and evaluation. Books were also excluded at the outset. Although the authors recognize the authority of books in shaping scholarly discourse, they were removed from analysis because books often span a variety of locations and subjects, especially when edited or authored by 
multiple people; and, for the most part, it was difficult to determine how much they relied upon the Visual Literacy Standards.

The study involved multiple structured searches rather than a single structured search to accommodate variations in citation styles, modifying the search phrase to 'visual literacy competency standards'. By dropping the 'acrl' in the exact phrase, each author discovered an average of 120 additional search results. This round of data collection also included searching across 13 additional library and information science databases, journals, and discovery tools (Appendix A). The authors found an additional 25 search results, exempting those that returned one or fewer results. After verifying results with each other and discarding duplicates, the authors identified 196 unique items total.

\section{Coding the data}

The authors of this study classified each item according to the following criteria:

1) Whether the Visual Literacy Standards were cited, mentioned, or the focus of the research;

2) The type of literacy (e.g., data literacy, digital literacy, information literacy, media literacy, visual literacy);

3) The discipline(s) of the research;

4) The subjects of the research (e.g., curriculum, graphic novels, infographics);

5) The educational audience (e.g., higher education, K-12, not addressed);

6) The type of research item (e.g., case study, empirical research, literature review, report, systematic review, teaching idea, theoretical research, viewpoint);

7) The country affiliated with the author(s) at the time of publication; 
8) The year of publication.

The authors determined how a scholar used the Visual Literacy Standards by examining whether they cited them, mentioned them, or based their research upon them. If the scholar referenced the Visual Literacy Standards via in-text citation, footnote, or bibliography, but did not substantially mention them beyond a brief reference, the authors considered them cited. If the scholar drew upon the Visual Literacy Standards in up to $25 \%$ of the article, the authors considered them mentioned. Finally, the authors considered a piece of scholarship to be based upon the Visual Literacy Standards when 50\% or more of the item's thesis relied upon them. The authors also determined the primary type of literacy mentioned in the item. Authors consulted keywords and the titles of the research item to determine the types of literacies addressed. In addition, they coded for various subjects and disciplines, according to The National Center for Education Statistics Taxonomy (2020), refining subjects iteratively within these broader categories (Appendix B). The authors included the type of library if they identified the discipline as library science. A critical distinction arose during coding between those items geared toward different audiences (K-12 or higher education). Therefore, the authors looked for indicators of audience in keywords or within the item itself. The authors classified items according to the type of research, modeled primarily after Emerald Publishers' categorization schema for articles: empirical research, viewpoint, case study, theoretical paper, and literature review. The authors added two additional categories after finding that some research items did not fit neatly into the other categories: teaching idea, modeled after the Journal of Visual Literacy; and systematic review, modeled after Elsevier Publishers (Appendix C). The authors gained a sense of the geographic 
reach of the Visual Literacy Standards through coding for the location in which the research was produced. To determine location, they coded for the country of the scholars' university affiliation at the time of publication. They also coded for the year of publication to get a sense of the Visual Literacy Standards' currency at the time of publication.

\section{Limitations}

Limiting the initial Google Scholar results to English contributed to the already prevalent bias toward English in Google Scholar and many search engines (Agrawal, Golshan \& Papalexakis, 2017). Results were likely personalized to the authors based on nationality, geolocation, and prior search behaviors, since both researchers were logged in under United States IP addresses and using their Google accounts the majority of the time (Robertson, Lazer, \& Wilson, 2018; Noble, 2018). Had the researchers used different search engines (e.g., Bing, DuckDuckGo, Firefox, Safari), in different countries, or from different accounts, the results would have varied (Devine \& Egger-Sider, 2014).

\section{Findings}

After coding 196 unique research items, the authors discovered nine different points of inquiry: the location in which the research was published; the year the research was published; the primary and secondary disciplines where visual literacy research is occurring; the types of literacies being researched; the educational audience for which the research is intended; subject categories and fields; how the Visual Literacy Standards were used, mentioned, or referenced in 
the research; the format and genre of the research; and finally, a correlation in the format of the research item and how the standards were implemented in the research.

\section{Location}

Not surprisingly, an overwhelming majority of items, over three-fourths, were published in the United States (149 items). The authors identified five other prominent countries, according to publication location: Turkey (7 items), Australia (5 items), Poland (5 items), and Spain (5 items). The authors identified sixteen other countries with four or fewer publications.

[Figure 1. Country Affiliation of the Author(s) near here]

\section{Year published}

The popularity of the Visual Literacy Standards in research items fluctuated over time. As expected, the years 2011 to 2014 saw an increase in usage as the standards gained in popularity. The year 2015 marked the highest use of the standards (38 items); however, the standards then declined again from 2016 (30 items) to 2017 (24 items). The standards saw a resurgence in 2018 (35 items), and it is yet to be determined if the increase will continue. It should be noted that 2019 (20 items) is only represented by six months, since data collection stopped on June 1, 2019.

[Figure 2. Year of Publication near here]

\section{Discipline}


The authors identified library science (100 items) as the primary discipline in over half of the research items. Education (46 items) was identified as the primary discipline in approximately a quarter of the research items. Seventeen other disciplines were also determined to be primary disciplines (See Table 1). The authors coded thirty research items as belonging to two primary disciplines, while one item was identified as having three primary disciplines. This multi-disciplinarity usually occurred when multiple authors collaborated from different fields.

[Table 1. Identified Disciplines near here]

\section{Type of literacy}

Almost every item had an identifiable type of literacy (171 items). The authors identified visual literacy as the primary literacy in the majority of items (112 items). Information literacy (24 items) trailed behind, followed by media literacy (14 items), and archival/primary source literacy (10 items). Data literacy (6 items), digital literacy (5 items), and data visualization literacy (1 item) were the least mentioned types of literacy identified by the authors. The authors designated 18 items as having multiple types of literacy. Information literacy and visual literacy overlapped the most.

[Figure 3. Types of Literacy near here]

\section{Educational audience}

Most of the research was conducted with a specific educational audience in mind. The data indicated that higher education (165 items) was the most frequent educational audience for visual 
literacy research, with K-12 (21 items) following. In a minority of cases, the research addressed both higher education and K-12 audiences (5 items). Research that did not address an educational audience (5 items) was also in the minority.

[Figure 4. Education Audience near here]

\section{Subjects}

The authors identified 19 secondary disciplines as subjects. visual and performing arts (13 items) and film/video and photographic arts (10 items) were identified the most frequently. The next most frequent subjects were: history (7 items), art history, criticism and conservation (6 items), graphic arts (5 items), and language/linguistics (5 items). Thirteen secondary disciplines were identified in three or fewer research items. The authors also determined that five different types of places, or settings in which the research was carried out, appeared in the literature. Academic libraries (74 items) were the most commonly mentioned place, followed by archives/special collections (17 items). The least mentioned places were museums (4 items), public libraries (1 item), and school libraries (1 item). Particular genres emerged as secondary subjects: graphic novels (11 items), infographics ( 7 items), and picture books ( 2 items). The last subject the authors coded for was "other," because the items did not fit into other categories. For this category, curriculum (41 items) was identified most often, followed by training (students, pre-service teachers, teachers) (23 items). The least mentioned subjects identified by the authors were gamification (4 items), career/leadership (3 items), collection development (1 item), and invention (1 item) (See Appendix A for each category of subjects). 


\section{Using the Visual Literacy Standards}

The majority of items (113 items) mentioned the Visual Literacy Standards, which usually occurred within the literature review followed by items that based their research on them, using them to ground their thesis (51 items). Items that referred to the standards only in a footnote or bibliography without giving greater context to the standards occurred the least (32 items).

[Figure 5: Using the Visual Literacy Standards near here]

\section{Type of research item}

The authors designated most items as empirical research (69 items), followed by case studies (51 items), and viewpoints (35 items). Theoretical papers (17 items) and teaching ideas (15 items) followed. The least identified type of research items were systematic reviews ( 5 items), literature reviews (4 items), and reports (2 items). In rare cases, there were research items that were classified as multiple types of research. For example, a case study was also classified as a theoretical paper, and a literature review was also categorized as empirical research because the items fit the definitions of both categories.

[Figure 6. Type of Research item near here]

\section{Type of research item and how the standards were used}

Research items used the Visual Literacy Standards differently. However, mentioning the standards was the most common use across all types of research items. Specifically, empirical 
research mentioned the standards the most often (40 items), rather than basing their research on the standards (17 items) or referring to the standards (12 items). While case studies mentioned the standards the most often (24 items), these research items based their research upon the standards far more often (19 items) than when referring to the standards ( 8 items). Viewpoints and theoretical papers followed the same pattern. Viewpoint items mentioned the standards the most often (19 items), followed by research items that based their research upon the standards (9 items), and items that refer to the standards ( 7 items). Theoretical papers mentioned the standards the most often (11 items), followed by research items that based their research upon the standards (4 items), and items that referred to the standards (2 items). Systematic reviews and literature reviews only mentioned the standards, (5 items) and (4 items), respectively. Reports were equally as likely to mention $(1$ item) or base their research on $(1$ item) the standards.

[Figure 7. Type of Research item and How the Standards were Used near here]

These points of inquiry reveal how educators, librarians, and scholars have used the Visual Literacy Standards over time and across multiple locations, disciplines, and contexts.

Additionally, the data gives some insight into how the Visual Literacy Standards have been used to ground research in disparate settings, geared toward various audiences, with vastly different research outputs.

\section{Discussion}

Paradigm shift 
The findings indicate that the field of library science uses the Visual Literacy Standards more than any other. This is not surprising, as the Visual Literacy Standards were created by and for librarians through the Association of College \& Research Libraries (ACRL), although research across a range of disciplines and subjects have begun to reference and use the standards. The data also show that academic libraries are the most common setting, followed by archives and special collections, which are usually affiliated with academic libraries.

Additionally, the authors found that the majority of items using the Visual Literacy Standards were published in the United States, with a steady increase in use from 2012 to 2015, just after their codification. The limited geographical uptake of the standards is partially due to the particular association which produced and published them. Although the ACRL has some international members, it is predominantly an American association, and therefore adopts standards and frameworks with an American mindset, collaborating with American stakeholders and constituents. Interestingly, the data show a steady decline in use from 2015 to 2017, which may be due to the ACRL's adoption of the Framework in 2016, and the broader shift in librarianship from applying standards and checklists to experimenting with conceptual frameworks for assessment and instruction, observed in Mackey and Jacobsen's Metaliteracy: Reinventing information literacy to empower learners (2014). The data also exhibit an overlap in information literacy and visual literacy research, most likely due to the fact that the Visual Literacy Standards was written as a companion document to the now rescinded Standards, and also because librarians tend to investigate visual literacy as a subset of information literacy. 
Moreover, the data reflect the fact that the Visual Literacy Standards were created for higher education settings. The majority of research items reference a higher education setting or adult audiences (ages 18 and up in a college or university setting). Matusiak and Heinbach likewise found that the majority of participants in the visual literacy studies they reviewed, published from 2011 to 2017, were undergraduate students, (2018). Since the ACRL is the official organization for college and research libraries, it stands to reason that college settings are the predominant setting found in these research items.

While not surprising, these findings are still significant. As an interdisciplinary field, visual literacy relies upon the cross-pollination of multiple communities and disciplines. One might have expected to find more discussion occurring internationally and across disciplines, given its beginnings and wide-ranging interdisciplinarity. Instead, it seems to have more firmly situated itself within the realms of library and information science and affiliated fields, within higher education, and within the United States. ${ }^{1}$

\section{Additional implications and opportunities}

Just as the results of this study showed that the research items were most likely to be published in the United States, Baylen and Lucas also found that the majority of research articles published between 2000 and 2014 (81 out of 129) on visual literacy were published by scholars working in the U.S. (2014). This finding has broader implications for the field in general and outside of

\footnotetext{
${ }^{1}$ Besides the American Library Association, the authors note that there are several other primarily library affiliated organizations in the United States, such as the Art Libraries Society of North America, the Visual Resources Association, and the Society of American Archivists who have supported publications and presentations on visual literacy. The International Visual Literacy Association and College Art Association, organizations for higher education and visual education, have also supported publications and presentations on visual literacy.
} 
librarianship. In order to expand the reach of the field, the International Visual Literacy Association, the oldest association based on the field of visual literacy, should be encouraged to invest in international partnerships in order to fulfill its mission. Its first joint conference with the European Network for Visual Literacy (ENViL) at the M Museum in Leuven, Belgium in 2019 shows promise in this direction.

In addition to the field of librarianship, the field of education also heavily utilizes the Visual Literacy Standards. This finding recalls Brumberger's conclusion that the majority of articles published in the Journal of Visual Literacy were pedagogical in nature, with "one constant [being] the persistent focus on teaching and learning" $(2019$, p. 10). Moreover, the authors most often categorized items according to the subjects: curriculum (development), and training (for students, pre-service teachers, teachers), reinforcing the historical, pedagogical nature of the visual literacy field. This finding indicates a challenge and an opportunity for the field at large: how do institutions and organizations partner across the full span of K-20 educational settings to center visual literacy instruction? This partnership between educators and librarians could radiate outwards to include other stakeholders and disciplines, creating multi- and interdisciplinary collaborations.

Finally, the majority of the items reviewed were empirical research, followed by case studies, most of which were also empirical in nature. In contrast, Baylen and Lucas (2014) and Brumberger (2019) found that the field of visual literacy generally lacks empirical research. However, Matusiak and Heinbach (2019) showed that "The proliferation of images and their increased use in academic and everyday information practices has sparked an interest in visual 
literacy as an area of research and library instruction" (p. 1). The data in this research study also demonstrate that the Visual Literacy Standards are being mentioned in research, usually within the literature review, while a smaller number of research items are basing their research upon the Visual Literacy Standards. These types of use indicate that the use of the standards are a third, separate thread in visual literacy research, in addition to the two threads the authors outline in the literature review. Researchers across all disciplines, following in the steps of librarians, can seize the opportunity to use the Visual Literacy Standards, uniting the field of visual literacy research in the process and moving the field past the definition problem of visual literacy.

\section{Conclusion}

The authors identified two threads in recent visual literacy scholarship where researchers have discovered similar trends in the literature and they have investigated the amount of empirical research being produced within the field of visual literacy. The results of this study provide a third thread: researchers can move the field towards a unified, organizing framework for its research by using the Visual Literacy Standards. The standards provide both an "outstanding starting point for designing applied research" (Brumberger, 2019, pg. 12) and a definition that the field can embrace. As this study shows, scholars from many different fields are beginning to use the Visual Literacy Standards to ground their research. As Kędra \& Žakevičiūtė note, "Implementation of the new practices in the twenty-first-century literacy education is demanding. It should be introduced in a systematic way rather than via ad hoc activities. It requires revolutionary thinking, assessing, grading and testing" (2019, p. 5). The Visual Literacy 
Standards provide a systematic set of visual literacy concepts to foster teaching, research, and assessment.

These skills are necessary for twenty-first-century learners, as the latest study from Project Information Literacy concludes: "[T]he news diet for many American college students today is an overwhelming and confusing stream of mediated and unmediated headlines, posts, alerts, tweets, visuals, and conversations that come to them in pieces throughout the day" (Head DeFrain, Fister, \& MacMillan, 2019, p. 14, emphasis added). In order to prepare visually literate individuals in the twenty-first century, the field of visual literacy must accommodate advances in media, political messaging, and technology by integrating the Visual Literacy Standards into current teaching and research practices. The Visual Literacy Standards allow librarians, educators, and scholars to meaningfully contribute to a complex, rapidly advancing information field that is actively working to address disinformation, bias, political rhetoric, artificial intelligence, social and new media, and information literacy. 


\section{Author Note}

Dana Statton Thompson has created the online bibliography, Recommended Reads for Visual Literacy, with support from a 2019 Carnegie-Whitney Grant from the American Library Association. The resource, part of the Visual Literacy Today online open-access journal, compiles a number of items focused on visual literacy within libraries and across disciplines, as well as research centered around the Visual Literacy Standards. Stephanie Beene has created a Zotero bibliography as a member of the second ACRL Visual Literacy Task Force to complement the Zotero bibliography created by the first ACRL Visual Literacy Task Force $(2019 ; 2011)$. Each of these resources provide easily accessible starting points for those looking to research visual literacy. 


\section{References}

Agrawal, R., Golshan, B., \& Papalexakis, E. E. (2017). Homogeneity in web search results:

Diagnosis and mitigation. ACM Transactions on Intelligent Systems and Technology,

8(5), 1-35. https://doi.org/10.1145/3057731.

Arksey, H., \& O’Malley, L. (2005). Scoping studies: Towards a methodological framework.

International Journal of Social Research Methodology, 8(1), 19-32.

Association of College \& Research Libraries (ACRL). (2000). Information literacy competency

standards for higher education. Retrieved July 24, 2019, from

http://hdl.handle.net/11213/7668

Association of College \& Research Libraries (ACRL). (2016). Framework for information

literacy for higher education. Retrieved July 24, 2019, from

http://www.ala.org/acrl/standards/ilframework

Association of College \& Research Libraries (ACRL). (2011). Visual literacy competency

standards for higher education. Retrieved July 11, 2019, from

http://www.ala.org/acrl/standards/visualliteracy 
Association of College \& Research Libraries (ACRL) Visual Literacy Task Force, \& Image

Resources Interest Group. (2010-2011). ACRL IRIG Visual Literacy Bibliography

[Bibliography]. Retrieved July 10, 2019, from the Zotero website:

https://www.zotero.org/groups/15454/acrl_irig_visual_literacy_bibliography/items?

Association of College \& Research Libraries (ACRL) Visual Literacy Task Force. (2019). ACRL

Visual Literacy Taskforce [Bibliography]. Retrieved July 10, 2019, from the Zotero website: https://www.zotero.org/groups/2264485/acrl_visual_literacy taskforce

Avgerinou, M., \& Ericson, J. (2002). A review of the concept of visual literacy. British Journal of Educational Technology, 28, 280-291. https://doi.org/10.1111/1467-8535.00035

Baylen, D. M. \& Lucas, K. (2014). Visualizing learning for the next generation: Visual and media literacy research, 2000-2014. 2014 Annual Proceedings - Jacksonville: Selected Research and Development Papers, 1, 37-47. https://members.aect.org/pdf/Proceedings/proceedings14/2014/14_06.pdf

Brill, J. M. \& Branch, R. M. (2007). Visual literacy defined - The results of a Delphi Study: Can IVLA (operationally) define visual literacy? Journal of Visual Literacy, 27(1), 47-60. https://doi.org/10.1080/23796529.2007.11674645. 
Brown, N. E., Bussert, K., Hattwig, D., \& Medaille, A. (2016). Visual Literacy for Libraries: A Practical, Standards-Based Guide. Chicago: The American Library Association.

Brumberger, E. (2019). Past, present, future: Mapping the research in visual literacy. Journal of Visual Literacy, 1-16. https://doi.org/10.1080/1051144X.2019.1575043

Clark-Baca, J., \& Braden, R. A. (1990). A Research Approach to the Identification, Clarification, and Definition of Visual Literacy and Related Concepts. In M. R. Simonson \& C. Hargrave (Eds.), Proceedings of Selected Research Paper Presentations at the Convention of the Association for Educational Communications and Technology and sponsored by the Research and Theory Division (Anaheim, California, January 31February 4, 1990). (pp. 25-41). https://eric.ed.gov/?q=\&id=ED323914.

Cochran, L. M. (1976). What is Visual Literacy. AECT Research and Theory Newsletter, 5(3), $2-3$.

Debes, J. L. (1969). The loom of visual literacy. Audiovisual Instruction, 14(8), 25-27.

Devine, J., \& Egger-Sider, F. (2014). Going Beyond Google Again: Strategies for Using and Teaching the Invisible Web. Chicago: ALA Neal-Schuman.

Grant, M. J., \& Booth, A. (2009). A typology of reviews: An analysis of 14 review types and 
associated methodologies. Health Information and Libraries Journal, 26(2): 91-108.

Hattwig, D., Bussert, K., Medaille, A., \& Burgess, J. (2013). Visual literacy standards in higher education: New opportunities for libraries and student learning. Portal: Libraries and the Academy, 13(1), 61-89. http://doi.org/10.1353/pla.2013.0008

Head, A. J., DeFrain, E., Fister, B., \& MacMillan, M. (2019). Across the great divide: How today's college students engage with news. First Monday, 24(8).

Institute of Education Sciences. (2020). National Center for Education Statistics: Classification of Instruction Programs (CIP 2020): List By Program Area [Taxonomy and Statistics]. https://nces.ed.gov/ipeds/cipcode/default.aspx?y=55

Khalil, H., Peters, M., Godfrey, C. M., McInerney, P., Soares, C. B., \& Parker, D. (2016). An evidence-based approach to scoping reviews. Worldviews on Evidence-Based Nursing, 13(2): 118-123.

Kędra, J. \& Žakevičiūtė, R. (2019). Visual literacy practices in higher education: What, why and how? Journal of Visual Literacy, 38 (1-2), 1-7. https://doi.org/10.1080/1051144X.2019.1580438

Mackey, T. P., \& Jacobson, T. E. (2014). Metaliteracy: Reinventing information literacy to 
empower learners. Chicago: The American Library Association.

Matusiak, K. K., \& Heinbach, C. (2018, August). Methodological approaches for exploring visual literacy practices. Paper presented at the 84th IFLA World Library and Information Congress (WLIC), Transform Libraries, Transform Societies - Kuala Lumpur, Malaysia, August 24-30, 2018. http://www.professionalabstracts.com/iflawlic2018/iplanner/\#/grid

Mackey, T. P., \& Jacobsen, T. E. (2019). Metaliterate learning for the post-truth world. Chicago: The American Library Association.

Marwick, A. \& Lewis, R. (2017). Media manipulation and disinformation online. Data \& Society Report, https://datasociety.net/output/media-manipulation-and-disinfo-online/

Michelson, A. (2017). A short history of visual literacy: The first five decades. Art Libraries Journal, 42(2), 95-98. https://doi.org/10.1017/alj.2017.10

Miller, C.R. (1984), Genre as social action, Quarterly Journal of Speech, 70(2), 151-167.

Munn, Z., Peters, M. D. J., Stern, C., Tufanaru, C., McArthur, A., \& Aromataris, E. (2018). Systematic review or scoping review? Guidance for authors when choosing between a systematic or scoping review approach. BMC Medical Research Methodology, 18. 
Noble, S. (2018). Algorithms of oppression: How search engines reinforce racism. New York:

New York University Press.

Pauwels, L. (2008). Visual literacy and visual culture: Reflections on developing more varied and explicit visual competencies. The Open Communication Journal, 2, 79-85.

https://doi.org/10.2174/1874916X00802010079

Peña Alonso, E. J. (2018). Visualizing visual literacy. (Dissertation, University of British Columbia). https://dx.doi.org/10.14288/1.0368982

Robertson, R. E., Lazer, D., \& Wilson, C. (2018). Auditing the personalization and composition of politically-related search engine results pages. Proceedings of the 2018 World Wide Web Conference - Lyon, France, April 23 - 27, 2018. (pp. 955-965).

https://doi.org/10.1145/3178876.3186143

Russo, A., Jankowski, A., Beene, S., \& Townsend, L. (2019). Strategic source evaluation: Addressing the container conundrum. Reference Services Review, 47 (3), 294-314. https://doi.org/10.1108/RSR-04-2019-0024

Serafini, F. (2017). Visual literacy. Oxford Research Encyclopedia of Education, 1-23.

Tewell, E. (2016). Toward the resistant reading of information: Google, resistant spectatorship, 
and critical information literacy. Portal: Libraries and the Academy, 16 (2), 289-310.

https://doi.org./10.1353/pla.2016.0017

Visual Literacy Today. (2019). Recommended Reads.

https://visualliteracytoday.org/recommended-reads/

Appendix A: Library and information science databases, journals, and discovery systems searched (in addition to Google Scholar) near here

Appendix B: Categories of research, analyzed by secondary discipline near here

Appendix C: Categories of research, analyzed by type near here 